\title{
Granulomatous (Crohn's) disease of the upper gastrointestinal tract: A study of 22 patients with mucosal granulomas
}

JoE SuKHABOte, MD, Hugh J FreEMAN, MD

J SUKHABOTE, HJ FREEMAN. Granulomatous (Crohn's) disease of the upper gastrointestinal tract: A study of 22 patients with mucosal granulomas. Can J Gastroenterol 1993;7(8):605-609. Gastroduodenal abnormalities may occur in patients with Crohn's disease and are usually associated with ileal or colonic involvement. This study examined clinical features in 22 patients with Crohn's disease involving the upper gastrointestinal tract seen at the University of British Columbia Hospital, Vancouver, British Columbia, from 1980-90. In all patients, the diagnosis was defined by the specific histological feature of mucosal granulomatous inflammation in the upper gastrointestinal tract, while other causes (such as sarcoidosis, tuberculosis and bacterial gut pathogens) were excluded. Patients with Crohn's disease and another gastroduodenal disorder (eg, peptic ulcer, erosions, gastritis, duodenitis) were excluded if granulomas were not detected. There were 10 males and 12 females, aged 15 to 57 years, at the time of detection of upper gastrointestinal tract granulomatous disease. In seven patients, disease was localized to the upper gastrointestinal tract: one, granulomatous oropharyngeal disease alone; five, granulomatous gastritis alone; one, granulomatous duodenitis alone. In three patients, granulomatous inflammatory disease was concurrently diagnosed in the upper and lower gastrointestinal tracts. In the remaining 11 patients, granulomatous disease in the upper gastrointestinal tract was detected after Crohn's disease was initially detected in the distal gastrointestinal tract: five, granulomatous gastritis alone; four, granulomatous duodenitis alone; two, both granulomatous gastritis and duodenitis. In one final patient, granulomatous oropharyngeal disease was detected in a buccal mucosal biopsy one year prior to diagnosis of Crohn's disease in the lower gastrointestinal tract. Upper abdominal pain was the most common symptom (over $90 \%$ of patients). Weight loss (over 50\%), nausea and vomiting (over 30\%) were also common and, occasionally, upper gastrointestinal tract bleeding (two patients) occurred. Endoscopic features included mucosal erosions, thickening of mucosal folds, ulceration, granularity, nodularity and cobblestoning. The most common radiographic change was mucosal thickening, but barium studies were most often normal. Patients have been followed for a mean of five years ( 1.5 to 11 years). One patient required surgical intervention to treat a duodeno-ileocolic fistula but this patient had a prior partial ileocolic resection and the fistula involved the intestinal anastomosis. The other 21

Department of Medicine (Gastroenterology), University Hospital and University of British Columbia, Vancouver, British Columbia

Correspondence and reprints: Dr Hugh Freeman, Head, Gastroenterology, ACU F-137, University Hospital (UBC Site), 2211 Wesbrook Mall, Vancouver, British Columbia V6T IW5. Telephone (604) 822-7216

Received for publication March 24, 1993. Accepted May 20, 1993
A NY SITE WITHIN THE GASTRO. intestinal tract may become involved with changes associated with Crohn's disease (1). It is well recognized that ileal and/or colonic disease are most often present, but occasionally 'isolated' changes may be detected localized to one or more sites in the upper and lower gastrointestinal tracts (2). In the past, gastric or duodenal granulomatous lesions were encountered only rarely although the clinical presentations were often stereotyped, especially in patients with well established Crohn's disease located in the small and large intestine. For example, clinical and radiological features of pyloric obstruction were frequently observed, requiring differentiation from peptic ulcer disease as well as infiltrative or neoplastic gastric disorders; sometimes this clinical presentation lead to surgical treatment, including partial gastrectomy or gastroenterostomy. In recent years, however, endoscopic biopsies of the stomach or duodenum have lead to increased detection of isolated mucosal granulomas requiring further evaluation, including consideration of Crohn's disease, sarcoidosis and other infectious causes of granulomatous gastritis or duodenitis (eg, histoplasmosis, yersiniosis).

Previous estimates suggest that approximately 0.5 to $4 \%$ of Crohn's disease patients may have gastroduodenal involvement $(1,2)$. The distal part of 
patients were treated with pharmacological agents for Crohn's disease as well as added medications including ranitidine in six patients, omeprazole in four, sulcralfate in one, and a combination of ranitidine and sucralfate in two. In conclusion, 22 patients with granulomatous mucosal inflammatory disease in the upper gastrointestinal tract typical of Crohn's disease were seen. A benign clinical course was observed, possibly reflecting an early pathological phase in the disease process. Extended long term follow-up of these patients might further delineate factors that could accurately define prognosis and determine the requirement for surgical treatment.

Key Words: Crohn's disease, Gastroduodenal Crohn's disease, Granulomas, Upper gastrointestinal tract Crohn's disease

\section{Maladie granulomateuse (de Crohn) des voies digestives supérieures : Étude portant sur 22 patients atteints de granulomes muqueux}

RÉSUMÉ : La maladie gastroduodénale peut survenir chez tout patient atteint de la maladie de Crohn et est habituellement associée à une atteinte de l'iléon ou du côlon. Cette étude s'est penchée sur les caractéristiques cliniques de 22 patients souffrant de la maladie de Crohn avec atteinte des voies digestives supérieures suivis à l'hôpital de l'Université de Colombie-Britannique à Vancouver (Colombie-Britannique) entre 1980 et 1990. Chez tous les patients, le diagnostic a été posé sur la base de signes histologiques spécifiques d'inflammation granulomateuse au niveau de la muqueuse des voies digestives supérieures, alors que d'autres causes (comme la sarcoídose, la tuberculose et les pathogènes intestinaux d'origine bactérienne) ont été exclues. Les patients atteints de la maladie de Crohn et d'autres troubles gastroduodénaux (par exemple, ulcères gastroduodénaux, érosions, gastrite, duodénite) ont été exclus si aucun granulome n'était décelé. Le groupe comptait 10 hommes et de 12 femmes âgés de 15 à 57 ans au moment du dépistage de la maladie granulomateuse des voies digestives supérieures. Chez sept patients, la maladie était localisée aux voies digestives supérieures seulement; l'un présentait une maladie granulomateuse oropharyngée seulement; cinq, une gastrite granulomateuse seulement; un, une duodénite granulomateuse seulement; chez trois patients la maladie inflammatoire granulomateuse s'observait concomitamment au niveau des voies digestives supérieures et inférieures; chez les onze patients restants, la maladie granulomateuse des voies digestives supérieures a été décelée après un dépistage initial de la maladie de Crohn au niveau des voies digestives distales. Cinq présentaient une gastrite granulomateuse seulement; quatre, une duodénite granulomateuse seulement; deux, une gastrite et une duodénite granulomateuses. Chez le dernier patient, la maladie oropharyngée granulomateuse a été dépistée par biopsie de la muqueuse buccale un an avant que ne soit posé le diagnostic de maladie de Crohn au niveau des voies digestives inférieures. La douleur abdominale haute a été le symptôme le plus fréquent (plus de $90 \%$ des patients), la perte de poids (plus de $50 \%$ ), les nausées et les vomissements (plus de $30 \%$ ) ont également été fréquents et une hémorragie des voies digestives hautes (chez deux patients) s'est produite. Les caractéristiques endoscopiques incluaient des érosions de la muqueuse, un épaississement des replis muqueux, des ulcérations et des anomalies granulaires et nodulaires, ainsi qu'un aspect pavimenteux de la muqueuse. Le signe radiologique le plus fréquent a été l'épaississement de la muqueuse, mais les épreuves au baryum ont été le plus souvent normales. Les patients ont été suivis en moyenne durant cinq ans ( 1,5 à 11 ans). Un patient a nécessité une intervention chirurgicale pour traiter une fistule duodéno-iléo-colique, mais ce patient avait déjà subi une résection iléo-colique partielle auparavant et la fistule mettait en jeu une anastomose intestinale. Les 21 autres patients ont été traités avec des agents pharmacologiques pour la maladie de Crohn et d'autres médicaments, notamment la ranitidine chez six patients, l'oméprazole chez quatre, le sucralfate chez un, et une association de ranitidine et de sucralfate chez deux. En conclusion, 22 patients atteints de maladie inflammatoire muqueuse granulomateuse des voies digestives supérieures typique de la maladie de Crohn ont été observés. On a noté une évolution clinique bénigne, possiblement proportionnelle au fait que le processus pathologique n'était pas très avancé. Un suivi à plus grande échelle et à plus long terme de ces patients pourrait permettre d'identifier certains facteurs pronostics plus précis à l'égard de cette maladie et déterminer la nécessité d'un traitement chirurgical. the stomach (3) is reported to be most frequently affected, but extensive disease - even resembling linitis plastica has been recorded $(4,5)$. Crohn's disease of the stomach may also occur alone, associated with lesions in the duodenum or more extensive disease elsewhere in the intestinal tract. Rarely, the duodenum may also be the only site (6), sometimes with only minimal endoscopic changes; thickening and nodularity of mucosal folds together with irregular ulcers and erosions are the most frequently reported endoscopic features in the absence of radiological changes (7). Granulomas in the duodenum may also be detected in the absence of clinical, radiological or endoscopic changes in the upper gastrointestinal tract in some patients with Crohn's disease documented elsewhere in the gastrointestinal tract (8). Indeed, this histological 'hallmark' of Crohn's disease, ie, the granuloma, may be detected in endoscopic biopsies even if the mucosa has a completely normal appearance (9).

In this report, the clinical features observed in 22 patients with the histological feature of mucosal granulomatous inflammation in the upper gastrointestinal tract are described; patients with Crohn's disease and other gastroduodenal abnormalities were excluded from evaluation in this study if granulomas were not detected that could be used as a histological marker of this inflammatory process. Based on the observations reported here, detection of granulomatous inflammation in the upper gastrointestinal tract may be a significant marker of a benign clinical course, even if more distal intestinal disease is evident.

\section{PATIENTS AND METHODS}

The records of Crohn's disease patients seen during the 10-year period from $1980-90$ at the authors' hospital were reviewed. Patients were seen and followed by a single gastroenterologist. Only patients with granulomatous inflammation in the upper gastrointestinal tract were included in this study. For each patient, serial microscopic sections of all mucosal biopsies were reexamined and the pathologist's origi- 
nal diagnosis of granulomatous inflammation in biopsies from the upper gastrointestinal tract confirmed. In most patients, multiple endoscopic ileal and/or colonic mucosal biopsies from normal and abnormal-appearing intestinal mucosa were also reviewed. For all upper gastrointestinal tract endoscopic procedures, at least two mucosal biopsies were evaluated from each site in the duodenum, gastric antrum and gastric body. In each case, definition of discrete noncaseating granulomas within the mucosa and containing one or more multinucleated giant cells was required. For each specimen, $5 \mu \mathrm{m} \mathrm{sec}$ tions were examined with hematoxylin and eosin; no parasites or foreign bodies were evident, and stains for acid-fast bacilli and fungi were negative. In addition, other gut bacterial pathogens, including yersinia species, were excluded. Patients with or without evidence of Crohn's disease elsewhere in the lower gastrointestinal tract using standard radiological, endoscopic and histological methods were included. Patients with established Crohn's disease and other gastroduodenal disorders, such as peptic ulcer disease, erosions, gastritis or duodenitis, were excluded from this study if granulomas were not detected in upper gastrointestinal tract mucosal biopsies.

\section{RESULTS}

Clinical features: Of the 22 patients, 12 were female and 10 were male (female:male ratio of 1.2:1). The median age when upper gastrointestinal tract disease was diagnosed was 24.6 years (range 15 to 57 ). In seven patients, disease was localized only to the upper gastrointestinal tract (one with granulomatous oropharyngeal inflammation alone, five with granulomatous gastritis alone, one with granulomatous duodenitis alone). In three patients, disease was diagnosed in both the upper and lower gastrointestinal tract concurrently (one with granulomatous oropharyngeal and colonic disease, one with granulomatous oropharyngeal and ileocolonic disease, one with granulomatous gastritis, granulomatous duodenitis and ileocolonic disease). In the remaining 11 patients, distal intestinal

TABLE 1

Clinical features of 22 patients

\begin{tabular}{lcccccc}
\hline Clinical feature & GG & GD & GD and GG & GOP & Total & Percentage \\
\hline Abdominal pain & 10 & 6 & 3 & 1 & 20 & 91 \\
Weight loss & 8 & 3 & 1 & 1 & 13 & 59 \\
Nausea and vomiting & 3 & 3 & 2 & 0 & 8 & 36 \\
Hemorrhage & 3 & 1 & 0 & 0 & 4 & 18 \\
Dysphagia & 0 & 0 & 0 & 2 & 2 & 9 \\
\hline
\end{tabular}

GD Granulomatous duodenitis; GG Granulomatous gastritis; GOP Granulomatous oropharyngeal inflammatory disease

\section{TABLE 2}

Comparison of endoscopic with radiological features

\begin{tabular}{lcccccccc}
\hline & \multicolumn{9}{c}{ Numbers of patients } \\
\multicolumn{1}{c}{ Lesions } & Rad & End & Rad & End & Rad & End & Rad & End \\
\hline Thickening & 2 & 2 & - & 1 & 2 & 2 & - & - \\
Erosions & - & 6 & - & 1 & - & 3 & - & - \\
Ulceration & 1 & 3 & - & - & 1 & 1 & - & - \\
Deformity & - & 1 & - & 1 & 1 & 1 & - & - \\
Granularity & - & - & - & 1 & - & 1 & - & - \\
Nodularity & - & - & - & 2 & - & - & - & - \\
Cobblestoning & - & - & - & - & - & 1 & - & - \\
Narrowing & 2 & 1 & - & - & - & - & - & - \\
Fistula & - & - & 1 & 1 & - & - & - & - \\
\hline
\end{tabular}

End Endoscopic features; GD Granulomatous duodenitis; GG Granulomatous gastritis; GOP Granulomatous oropharyngeal inflammatory disease; Rad Radiological features

disease was documented prior to the development of upper gastrointestinal tract disease (five with granulomatous gastritis alone, four with granulomatous duodenitis alone, and two with granulomatous gastritis and granulomatous duodenitis). Of these patients, upper gastrointestinal tract disease was detected from 1.5 to 11 years (mean five years and median four years) after the diagnosis of ileo- and/or colonic disease was established. In the one additional patient, granulomatous oropharyngeal inflammatory disease was detected about one year prior to the detection of lower gastrointestinal tract disease.

The most common location of gastric mucosal involvement by granulomatous inflammation was the distal gastric antrum (54\%). In one patient, granulomatous inflammation was confined to the gastric body mucosa. These histological observations related to granulomatous inflammation seem to confirm previous reports based largely on endoscopic and radiological documentation in patents with established Crohn's disease in the distal small in- testine and/or colon. Duodenal involvement was detected in eight patients (36\%). Of these, six had lesions confined to the duodenal bulb and the other two patients had distal duodenal involvement.

Table 1 lists the clinical features of the 22 patients with granulomatous mucosal inflammatory disease of the upper gastrointestinal tract. The most common symptom was upper abdominal pain, often simulating peptic ulcer disease. Nausea, vomiting and weight loss were detected in about two-thirds of the patients. Upper gastrointestinal tract bleeding was detected in four patients, but only one patient with granulomatous gastritis had bleeding that required transfusion replacement therapy. Dysphagia and dysphonia were observed in two patients with granulomatous oropharyngeal disease. Other systemic symptoms included fever, malaise, anorexia and arthralgias. No patient in this series was observed with other extra-intestinal manifestations of Crohn's disease (ie, hepatobiliary tract disease, arthritis, spondylitis). 
Radiological features: All patients in this study had barium contrast studies of the upper gastrointestinal tract, including the small intestine. Radiological studies were done within two months of endoscopic and/or biopsy studies. Of these, only 10 had abnormal radiological findings. The most commonly described abnormal radiological feature was thickened mucosal folds. In two patients with granulomatous gastritis, narrowing of the distal gastric antrum was described. Ulceration in the upper gastrointestinal tract was noted in two patients. Deformity of the duodenal bulb was reported in one patient. Other abnormal features included a duodenoileocolonic fistula in one patient and a malabsorption pattern in one patient. Changes of cobblestoning, fissures and/or mucosal nodularity were not described. In one patient with colonic Crohn's disease, changes in the upper respiratory tract, specifically the larynx, were defined radiologically and have been described elsewhere (10).

Endoscopic features: Endoscopic examination of the upper gastrointestinal tract was done in 21 patients. An abnormal study was reported in 19 patients $(86 \%)$. Gastric and/or duodenal erosions were the most commonly described features (47.7\%). Other changes of the mucosa that were described included thickened mucosal folds (25\%), mucosal erythema (25\%), ulceration $(20 \%)$, granularity $(10 \%)$ and nodularity (10\%). In one patient, cobblestoned duodenal mucosa was described. In one patient with colonic Crohn's disease and upper respiratory tract changes, thickened uvular and arytenoid folds were detected. Another patient was found to have a fistulous tract from the descending duodenum to the site of a previous ileocolonic anastomosis.

Table 2 compares the radiological and endoscopic descriptions in patients with granulomatous gastritis and/or granulomatous duodenitis; for these entities, endoscopy appeared to be more sensitive than radiological methods for detection of specific abnormalities, except for luminal narrowing in granulomatous gastritis.

Treatment: The 22 patients in this study have all been followed primarily in an out-patient setting for a mean of five years (range 1.5 to 11 ). Only one patient required surgical intervention to repair a duodeno-ileocolonic fistula. The remaining 21 patients have received a variety of pharmacological agents - these have included different medications for Crohn's disease, including metronidazole, corticosteroids, sulphasalazine and azathioprine, primarily in patients with distal intestinal disease. In one patient with isolated granulomatous oropharyngeal disease, prednisone was administered. In two patients with granulomatous oropharyngeal disease and associated intestinal involvement, prednisone and sulphasalazine were used. In those patients with either granulomatous gastritis and/or granulomatous duodenitis, several pharmacological measures were used, primarily to control symptoms; these included ranitidine in six patients, cimetidine in one, omeprazole in four, sucralfate in one and sucralfate with ranitidine in two. Although the effects of each of these agents was not systematically studied, none of the 21 patients has subsequently required a surgical procedure.

\section{DISCUSSION}

This study explored clinical, radiological and endoscopic features observed in 22 patients with granulomatous inflammatory disease of the mucosa in the upper gastrointestinal tract. The presence of granulomas, although not pathognomonic, is a characteristic histological finding in endoscopic mucosal biopsies from patients with Crohn's disease. Granulomas have particular significance if other disease processes with granulomatous inflammation (as in the present study) are excluded, in particular, sarcoidosis and infectious causes, such as tuberculosis or yersiniosis. In this study, we reviewed our clinical records for the patient population with inflammatory bowel disease seen from $1980-90$ by one of the authors and estimated an overall prevalence of about 1 to $2 \%$. Most studies of patients with Crohn's disease sug. gest that the incidence of upper gastrointestinal tract involvement is higher; the lower figure reported here reflects, in part, the authors' determination to maintain a rigid histological requirement for mucosal granulomas in biopsy material so that a 'reagent-grade' patient population could be defined for evaluation. In this study, patients with established Crohn's disease and radiological and/or endoscopic changes in the upper gastrointestinal tract were excluded from this evaluation if microscopic evidence for granulomatous inflammation could not be demonstrated.

Clinically, most patients presented with upper abdominal pain, often localized to the epigastric area. Postprandial discomfort, pain relief with food or antacids, as well as associated nausea and vomiting were observed. In some patients, this suggested features of gastric outlet obstruction (6). Significant weight loss was also seen in up to $50 \%$ of patients, possibly reflecting impaired food intake and impaired gastric emptying of nutrients into the small intestine. Upper gastrointestinal hemorrhage requiring transfusion was observed in only a single patient in this series while less significant bleeding events were also infrequent. This is consistent with other reports $(11,12)$, although major hemorrhage in either gastric or duodenal Crohn's disease can occur $(13,14)$. Dysphagia and dysphonia were also observed in some patients in this study with oropharyngeal disease. In one of these patients, disease extended into the upper respiratory tract (9). Although significant symptoms could be attributed to the upper gastrointestinal tract in these patients, recognition of gastroduodenal disease could have been delayed, in part, because clinical features often may be overshadowed by diarrhea or other symptoms attributed to small or large intestinal disease.

Radiological features of Crohn's disease, including mucosal thickening, luminal narrowing and ulceration, were similar to those described elsewhere in the lower gastrointestinal tract (15. 19). In this study of granulomatous inflammatory disease, over $50 \%$ of the patients with barium contrast studies had normal findings. In those with abnormal studies, changes most often 
were thickened mucosal folds while mucosal erosions and ulceration, readily detected by endoscopic examination, were not seen. Other changes in the mucosal pattern, such as nodularity, granularity and cobblestoning, were also best visualized by endoscopic evaluation. Although contrast studies may be superior for evaluation of stenosing lesions in the gastroduodenal region (7), only one patient in this study had a normal mucosal appearance described on upper endoscopic examination. Detection of granulomatous inflammation in endoscopic biopsies, despite normal macroscopic appearances, has been previously reported (8). In this study, the most common site of involvement with granulomatous inflammation in the mucosa was the distal gastric antrum $(56 \%)$ while duodenal disease was detected in eight patients (36\%), mostly confined to the duodenal bulb. This distribution of granulomatous inflammatory disease would be consistent with earlier de-

ACKNOWLEDGEMENTS: Supported by a research and development grant from Pharmacia (Canada) Inc, Baie d'Urfe, Quebec.

\section{REFERENCES}

1. Freeman HJ. Definition of inflammatory bowel disease. In: Freeman HJ, ed. Inflammatory Bowel Disease, vol 1. Boca Raton: CRC Press, 1989:3-7.

2. Freeman HJ. Upper gastrointestinal tract Crohn's disease. Can J Gastroenterol 1990;4:26-30.

3. Danzi JT, Farmer RG, Sullivan BH, Rankin GB. Endoscopic features of gastroduodenal Crohn's disease. Gastroenterology 1976;70:9-13.

4. Johnson OA, Hoskins DW, Todd J, Thorbjarnarson B. Crohn's disease of the stomach. Gastroenterology 1966;50:571-7.

5. Johnson FW, Delaney JP. Regional enteritis involving stomach. Arch Surg 1972;105:434-7.

6. Nugent FW, Richmond M, Park SK. Crohn's disease of the duodenum. Gut 1977;18:115-20.

7. Rutgeerts P, Onette E, Vantrappen G, Geboes K, Broeckaert L, Talloen L. Crohn's disease of the stomach and duodenum: A clinical study with emphasis on the value of endoscopy scriptions, largely based on radiological and/or endoscopic studies, of the preferential sites of detection of Crohn's disease in the upper gastrointestinal tract (2).

In this study, only one patient required surgical treatment for Crohn's disease. This patient had a prior ileocolonic resection and then developed a fistulous tract between the duodenum and the ileocolonic anastomosis; as a result, another resection was needed. All other patients in this study have been treated solely with traditional pharmacological measures for Crohn's disease and in some, but not all, medications for symptomatic management of gastroduodenal disease. Although $\mathrm{H}_{2}$-receptor antagonists and omeprazole $(2,20,21)$ may have value in the management of these patients, the role of each of these specific pharmacologi$\mathrm{cal}$ approaches to management of gastroduodenal disease in this setting was not systematically addressed in the present study. The duration of follow-up in

and endoscopic biopsies. Endoscopy 1980;12:288-94.

8. Korelitz BI, Waye JD, Kruening J, et al. Crohn's disease in endoscopic biopsies of the gastric antrum and duodenum. Am J Gastroenterol 1981;76:103-9.

9. Surawicz CM, Meisel JL, Ylvisaker T, Saunders DR, Rubin CE. Rectal biopsy in diagnosis of Crohn's disease: Value of multiple biopsies and serial sectioning. Gastroenterology 1981;80:66-71

10. Li D, Freeman HJ. Laryngeal Crohn's disease. Am J Roentgenol. (In press)

11. Nugent FW, Roy MA. Duodenal Crohn's disease: An analysis of 89 cases. Am J Gastroenterol 1989;84:249-54.

12. Tootla F, Lucas RJ, Bernack EG. Gastroduodenal Crohn's disease. Arch Surg 1976;111: 855-7.

13. Kim US, Zimmerman MJ, Weiss M. Massive upper gastrointestinal hemorrhage associated with Crohn's disease of the stomach and duodenum: A case report. Am J Gastroenterol 1973;59:244-9.

14. Bruyns E, Lubber ES, van Tongeren JH. Major hemorrhage in Crohn's disease. Neth J Med 1979;22:67-71.

15. Legge DA, Carlson HC, Judd ES. Roentgenologic features of regional enteritis of the upper gastrointestinal tract. Am J Roentgenol 1970;110:355-60. this series of patients has been limited, and it may be that additional patients will develop changes (such as obstruction) that will require surgical intervention. The findings here need to be interpreted cautiously since the present patients were not necessarily at the same stage in their disease. It seems that granulomatous gastritis and/or granulomatous duodenitis have a relatively benign clinical course, even in patients with established Crohn's disease elsewhere in the gastrointestinal tract. As previously suggested, the specific microscopic marker chosen in this study to define the patient population, ie, the mucosal granuloma, may be an early histological feature in the development of the pathological changes associated with Crohn's disease (22). If this is indeed the case, then following the present patients may be useful to determine further the natural history of granulomatous inflammatory disease in the upper gastrointestinal tract.

16. Nelson SW. Some interesting and unusual manifestations of Crohn's disease (regional enteritis) of the stomach, duodenum, and small intestine. Am J Roentgenol 1969;17:86-101.

17. Bagby RJ, Roger JV, Hobb C. Crohn's disease of the esophagus, stomach, and duodenum. A review with emphasis on the radiographic findings. South Med J 1972;65:515-23.

18. Thomson WM, Cockrill H, Rice RP. Regional enteritis of the duodenum. Am J Roentgenol 1975;123:252-61.

19. Miller EM, Moss AA, Kressel HY. Duodenal involvement with Crohn's disease. A spectrum of radiographic abnormality. Am J Gastroenterol 1979;71:107-16.

20. Dobbins WO. Gastroduodenal Crohn's disease. In: Bayless TM, ed. Current Management of Inflammatory Bowel Disease. Philadelphia: BC Decker, 1989:218-20.

21. Woolfson K, Greenberg GR. Symptomatic improvement of gastroduodenal Crohn's disease with omeprazole. Gastroenterology 1989;96:A551.

22. Kelly JK, Sutherland LR. The chronological sequence in the pathology of Crohn's disease. J Clin Gastroenterol 1988;10:28-33. 


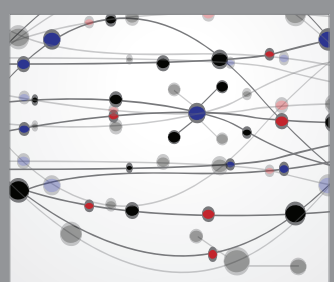

The Scientific World Journal
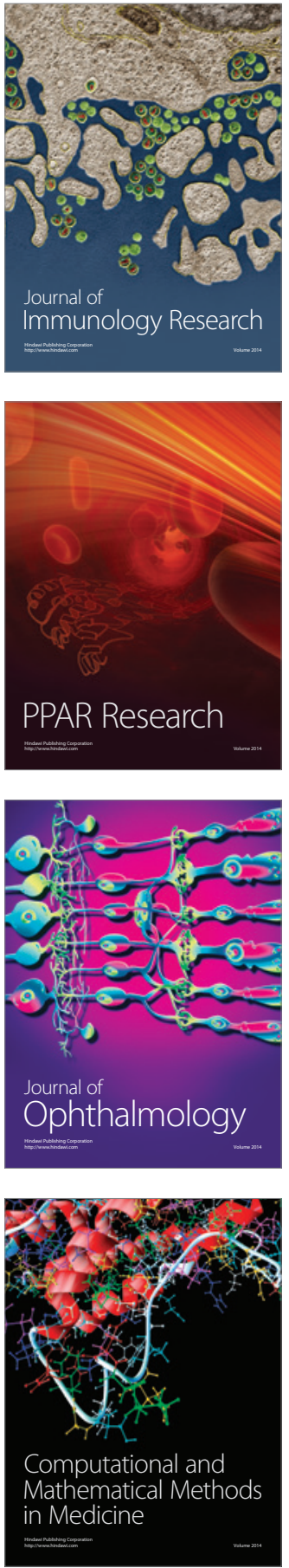

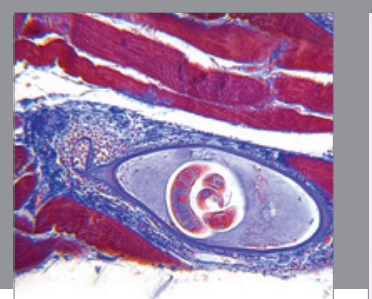

Gastroenterology Research and Practice

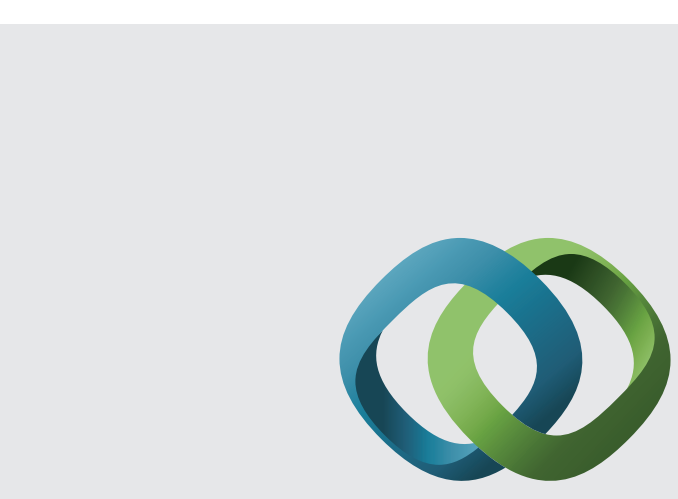

\section{Hindawi}

Submit your manuscripts at

http://www.hindawi.com
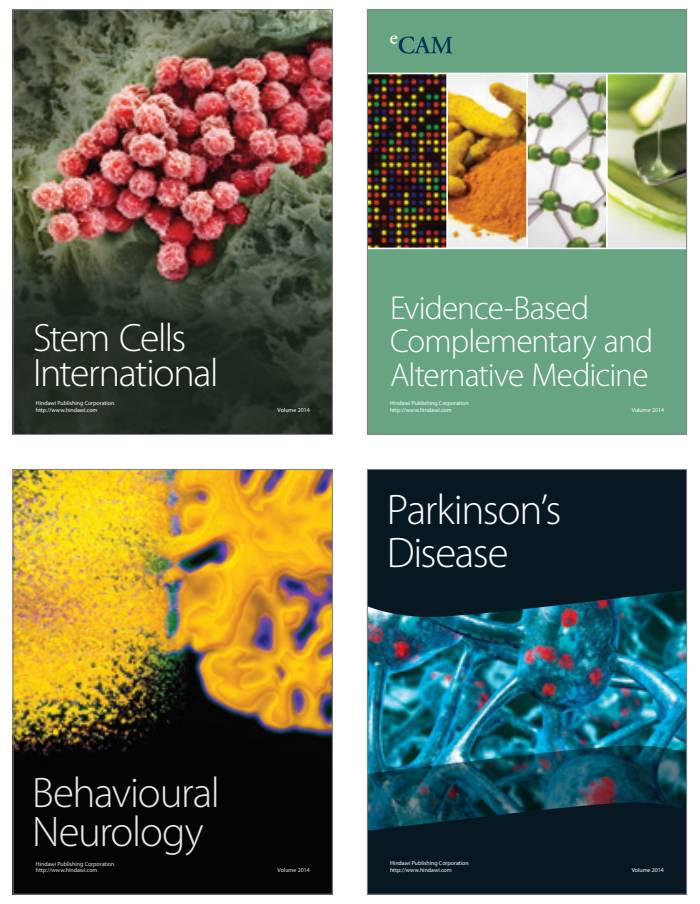
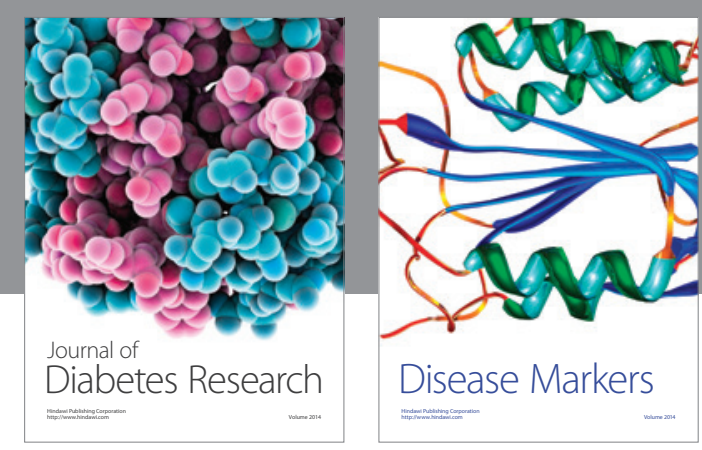

Disease Markers
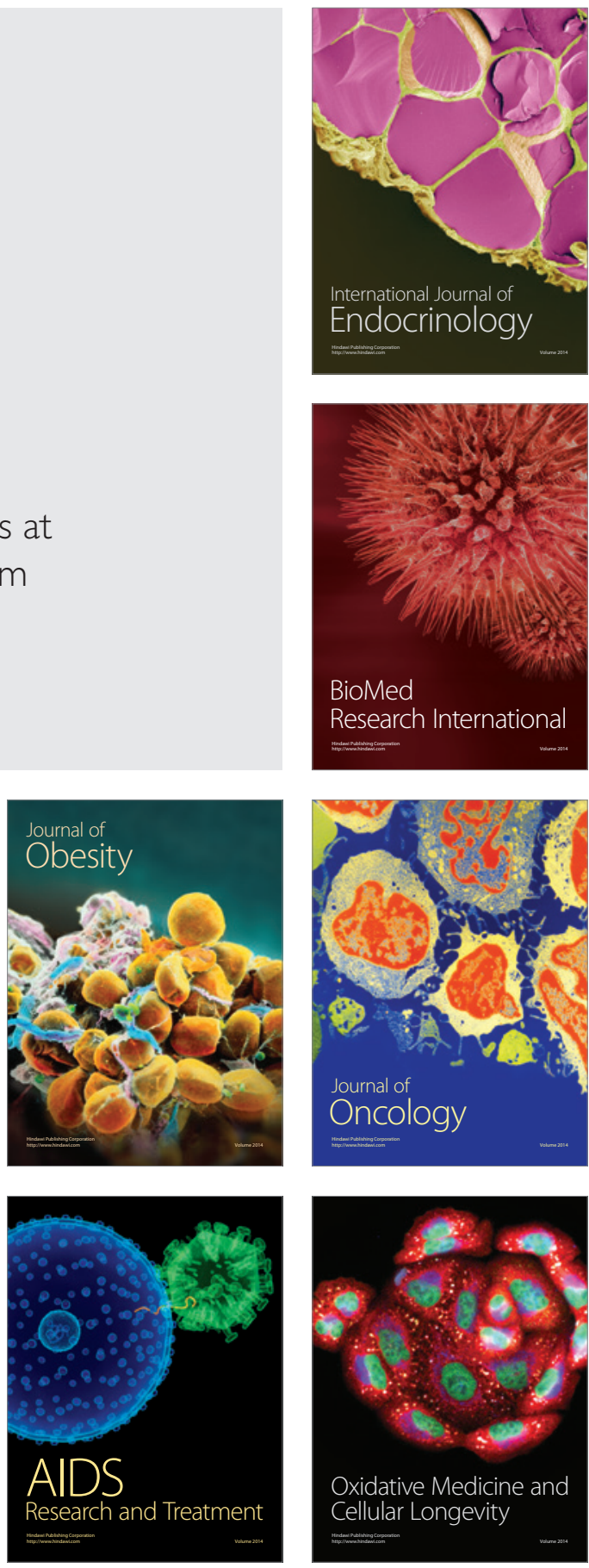